\title{
Melatonin Protects the Heart, Lungs and Kidneys from Oxidative Stress under Intermittent Hypobaric Hypoxia in Rats
}

\author{
Jorge G. Farías ${ }^{1}$, Andrea B. Zepeda ${ }^{1}$ And Gloria M. Calaf', 3 \\ ${ }^{1}$ Facultad de Ingeniería, Departamento de Ingeniería Química, Ciencias y Administración, Universidad de La Frontera, Casilla 54-D, Temuco, Chile. \\ 2 Instituto de Alta Investigación, Universidad de Tarapacá, Arica,-Chile. \\ ${ }^{3}$ Center for Radiological Research, Columbia University Medical Center, New York, NY, USA.
}

\begin{abstract}
Melatonin (N-acetyl-5-methoxytryptamine) is the main secretory product of the pineal gland in all mammals including humans, but it is also produced in other organs. It has been previously demonstrated to be a powerful organ-protective substance under oxidative stress conditions. The aim of this study was to evaluate the protective effect of melatonin in several organs such as heart, lung, kidney, and of the reproductive system, such as testis and epididymis in animals exposed to intermittent hypobaric hypoxia and therefore exposed to oxidative stress and analyzed by lipid peroxidation. Ten-week-old male Wistar rats were divided into 6 groups for 96 hours during 32 days under: 1) Normobaric conditions, 2) plus physiologic solution, 3) plus melatonin, 4) intermittent hypobaric hypoxia, 5 plus physiologic solution and 6) plus melatonin. The animals were injected with melatonin (10 mg/kg body weight) at an interval of 96 hours during 32 days. Results indicated that melatonin decreased lipid peroxidation in heart, kidneys and lung under intermittent hypobaric hypoxia conditions. However, it did not exhibit any protective effect in liver, testis, epididymis and sperm count.
\end{abstract}

Key words: intermittent hypobaric hypoxia, lipid peroxidation, melatonin, oxidative stress

\section{INTRODUCTION}

Oxidative stress can be triggered by a series of endogenous and exogenous factors, including exposure to high altitude. Exposure to high altitudes has been associated with an increase in the production of reactive oxygen species that are generated during the re-oxygenation phase of intermittent continuous hypobaric hypoxia and contribute to physiological responses (Nanduri et al., 2008: Farias et al., 2005a). The highly reactive property and oxidative capability that characterize the reactive oxygen species and the free radicals result in overall damage that affects the main cell components and tissues (Blokhina et al., 2003; Radak et al., 1997; Nakanishi et al. 1995; Radak et al., 1994). The use of antioxidants in pharmacological concentrations to reduce the effects of intermittent hypobaric hypoxia by oxidative stress has been reported (Vagas et al., 2011, Farias et al., 2010). Oxidative stress per se may be associated with complications such as myocardial injury, pulmonary edema, kidney and liver failure, and increased mortality (Kücükakin et al., 2007).

Melatonin (N-acetyl-5-methoxytryptamine) is the main secretory product of the pineal gland in all mammals including humans, but it is also produced in other organs (Okutan et al., 2004). It is a highly effective antioxidant, scavenging hydroxyl radicals and inhibiting the production of nitric oxide (Gitto et al., 2011; Serel et al., 2004) and other antioxidants like vitamins E and C (Kücükakin et al., 2009). The ability of melatonin to counteract ROS formation is due to the special characteristic of this substance to cross morpho and physiological barriers distributed in tissues, cells and sub-cellular compartments due to its distinct physical and chemical properties (Costa et al., 1995; Tomás-Zapico et al., 2005). In addition, the "hormone of darkness" and messenger of the photoperiod is also well known to exhibit strong direct and indirect antioxidant properties, one of which is capturing ROS directly and another is stimulating gene expression and the activity of some enzymes that can activate enzymatic antioxidants (Kücükakin et al., 2009). This demonstrates that the surgical removal of the pineal gland, one source of melatonin, exacerbates the tissue damage caused by free radicals (Reiter et al., 2001). Melatonin has previously been demonstrated to be a powerful protective substance in numerous injury models as ischemia/ reperfusion, where it is cardio-protective in both physiological and pharmacological concentrations. These beneficial effects have been attributed to the capacity of this hormone to act as a radical scavenger (Kücükakin et al., 2009; Mathes, 2010).

During the last 20 years, intensive mining activity has been developed in Chile, particularly in the Andean mountain range, where the altitude is over 4,000 meters above sea level. It is estimated that there is a working population of over 55,000 who are exposed to hypobaric hypoxia (high altitude sickness). Miners work under these conditions for 4 to 20 days, followed by days off at sea level, and this is repeated over several years (Jalil et al., 1994, Germack et al., 2002; Richalet et al., 2002). Intermittent exposure to high altitudes is virtually unknown to date; however it is an unusual condition for workers involving a series of changes at the physiological and cellular levels aimed to compensate the decrease in partial oxygen pressure $\left(\mathrm{PO}_{2}\right)$. On the other hand, exposure at 7,576 m.a.s.l. for 5 days caused an increase in lipid peroxidation in the plasma of rats (Kumar et al., 1999). It has been previously shown that melatonin can also protect tissues from oxidative damage (e.g: testicles) under intermittent hypobaric hypoxia conditions (Bustos-Obregón et al., 2010; Hartley et al., 2009). The aim of this study was to evaluate the protective effect of melatonin in several organs, such as heart, lung, kidney, and reproductive system as testis and epididymis in animals exposed to IHH and therefore exposed to oxidative stress. 
MATERIAL AND METHODS

\section{Experimental design}

Ten-week-old male Wistar rats $(246 \pm 11 \mathrm{~g}$; $\mathrm{n}=36)$ were obtained from the Animal Facility at the University of Valparaiso. Rats were housed under a 12L: 12D cycle, with water and rat chow being provided ad libitum. They were killed by cervical dislocation. All procedures were performed in agreement with the Principles of Laboratory Animal Care, advocated by the National Society of Medical Research, and the Guide for the Care and Use of Laboratory Animals (Institute of Animal Laboratory Resources, 1996). Rats were divided into 6 groups (6 rats per group): 1) normobaric conditions (Nx), 2) $\mathrm{Nx}+$ physiologic $\mathrm{NaCl}$ solution $(\mathrm{Nx}+\mathrm{PS}), 3) \mathrm{Nx}+$ Melatonin $(\mathrm{Nx}+\mathrm{Me}), 4)$ intermittent hypobaric hypoxia $(\mathrm{IHH}), 5) \mathrm{IHH}+\mathrm{PS}$, and 6) $\mathrm{IHH}+\mathrm{Me}$. A 3x2-factorial experimental design was used to consider 3 injection treatments (no injection, PS, and Me) and 2 environmental treatments ( $\mathrm{Nx}$ and $\mathrm{IHH}$ ). The animals were intraperitoneally injected melatonin $(10 \mathrm{mg} / \mathrm{kg}$ body weight) or vehicle $(0.1 \mathrm{~mL}$ of PS) at intervals of 96 hours. The IHH group of animals were exposed to hypobaric hypoxia for 96 hours (428 torr; PO2 $89.6 \mathrm{~mm} \mathrm{Hg}$ ) followed by the Nx condition for 96 hours ( 96 hours of hypoxia/96 hours of normoxia) for a total period of 32 days. Pressure changes in the hypobaric chamber were achieved by steps of $150 \mathrm{~mm} \mathrm{Hg}$ per minute, which simulated altitude changes. The Nx animals were housed in the same room next to the IHH animals.
Determination of Thiobarbituric Acid-Reactive Substances (TBARS)

Body weight was determined 32 days after initiation of the protocol. Rats were then killed by cervical dislocation, and the different organs were collected in phosphate-buffered saline (PBS; pH 7.2). Determination of thiobarbituric acidreactive substances (TBARS) was undertaken as an index of lipid peroxidation. TBARS were estimated at $532 \mathrm{~nm}$, and their concentrations were calculated using a molar extinction coefficient of $1.56 \times 10^{5} \mathrm{M}^{-1} \mathrm{~cm}^{-1}$ obtained utilizing malondialdehyde (MDA; Sigma-Aldrich, St Louis, Missouri) as a standard (Farias et al., 2010). The results were expressed as nmol of MDA equivalents/mg tissue.

\section{Isolation and sperm count}

Sperm count was performed as previously described (Farías et al., 2010). Briefly, epididymal spermatozoa were separated by cutting the caudal epididymis into segments of approximately $1 \mathrm{~mm}^{3}$ with a sharp razor blade in $1 \mathrm{~mL}$ of PBS ( $\mathrm{pH} \mathrm{7.2).}$ Spermatozoa from caudal regions were completely removed by vortexing gently in PBS, and the tissue debris was allowed to settle for 5 minutes. Spermatozoa released in the buffer were aspirated, centrifuged at $800 \mathrm{xg}$ for 15 minutes, and used for biochemical determinations. All of these procedures were performed at $4^{\circ} \mathrm{C}$. The number of sperm in the suspension was counted using a Neubauer chamber.
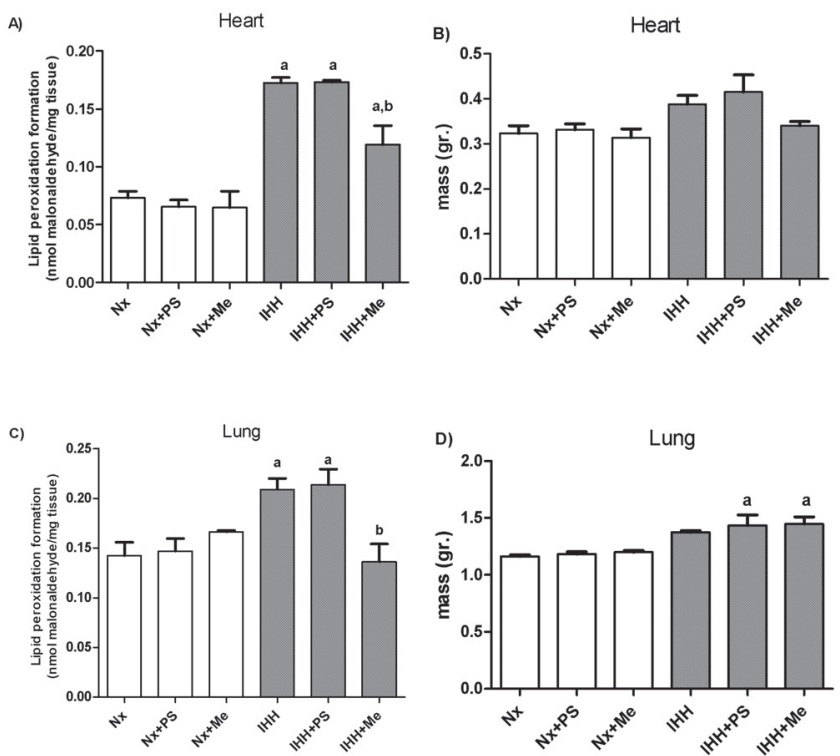

Figure 1. Levels of lipid peroxidation and organ size in heart and lung after IHH: Rats were submitted to intermittent hypobaric hypoxia $(\mathrm{IHH})$ or normobaric $(\mathrm{Nx})$ condition, with or without treatment of melatonin (Me). PS: rats treated with physiological $\mathrm{NaCl}$ solution. At the end of treatment (32 days), lipid peroxidation and organ size were determined in heart $(A, B)$ and lung $(C, D)$. Bars indicate the mean SD $(n=6)$. a $p<0.05(H x$ versus $\mathrm{Nx}) ; \mathrm{b} \mathrm{p}<0.05$.
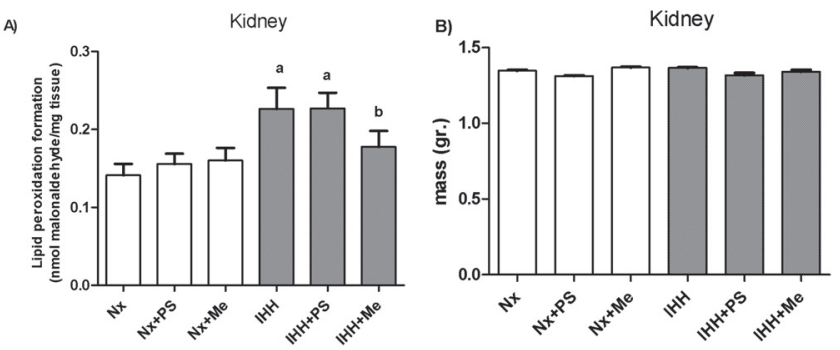

c)
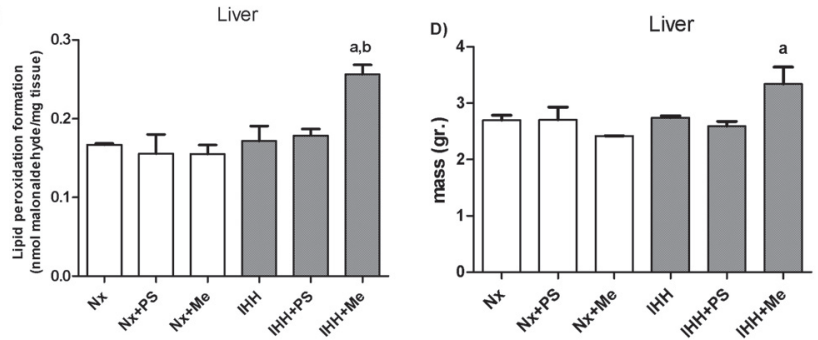

Figure 2. Levels of lipid peroxidation and organ size in kidney and liver after IHH: Rats were submitted to intermittent hypobaric hypoxia $(\mathrm{IHH})$ or normobaric $(\mathrm{Nx})$ condition, with or without treatment of melatonin (Me). PS: rats treated with physiological $\mathrm{NaCl}$ solution. At the end of treatment (32 days), lipid peroxidation and organ size were determined in kidney $(A$, $B)$ and liver $(C, D)$. Bars indicate the mean SD $(n=6)$. a $p<0.05(H x$ versus $\mathrm{Nx}) ; \mathrm{b} \mathrm{p}<0.05$. 


\section{Statistical analysis}

The results were analyzed using a 2-way variance analysis (ANOVA) followed by a Bonferroni analysis. The level of statistical significance was set at $\mathrm{p}<0.05$. The data were analyzed using the GraphPad Prism software version 4.0 (GraphPad Software, San Diego, California). The results are presented as means \pm standard deviation (SD).

\section{RESULTS}

Determination of thiobarbituric acid-reactive substances (TBARS) was undertaken as an index of lipid peroxidation. The present results show that intermittent hypobaric hypoxia induced lipid peroxidation in heart in comparison to normoxic $(\mathrm{Nx})$ conditions as indicated by the levels of TBARS $(\mathrm{P}<0.05)$ and shown in Figure 1A. However, melatonin diminished such effect that was corroborated by a decrease in mass of the organ (Figure 1B). Similar results were observed in lung $(\mathrm{P}<0.05)$ as shown in Figure 1C: However, but there was a significant $(\mathrm{P}<0.05)$ increase in the mass of such organ (Figure 1D).

Lipid peroxidation in kidneys has been found to under IHH conditions more than under $\mathrm{Nx}$ conditions $(\mathrm{P}<0.05)$ as shown in Figure 2A. It is interesting to note that there was a decrease induced by melatonin $(\mathrm{P}<0.05)$. However, there was no significant difference in organ mass $(P>0.05)$, as can be observed in Figure 2B. Figure $2 \mathrm{C}$ shows that there was no significant difference in lipid peroxidation in the liver under $\mathrm{IHH}$ and $\mathrm{Nx}$ conditions $(\mathrm{P}>0.05)$. However, there was an increase in lipid peroxidation in melatonin-treated animals, compared to the $\mathrm{Nx}$ and $\mathrm{IHH}$ treated groups $(\mathrm{P}<0.05)$. As well, the lipid peroxidation in the melaton-treated group was accompanied by an increase in organ mass $(\mathrm{P}<0.05)$, as shown in Figure 2D.

Figure $3 \mathrm{~A}$ shows that $\mathrm{IHH}$ induced a significant $(\mathrm{P}<0.05)$ increase in lipid peroxidation in testis in comparison to $\mathrm{Nx}$ conditions. Melatonin did not have any effect, but there was a decrease in organ mass $(\mathrm{P}<0.05)$ compared to $\mathrm{IHH}$ conditions (Fig3 B). Similar results were observed in epididymis $(\mathrm{P}<0.05)$ in comparison to $\mathrm{Nx}$ (Fig 3C), although there was no significant difference (Fig3D) in organ mass $(\mathrm{P}>0.05)$. There was a nonsignificant difference in sperm counts under Nx conditions. However, there was a decrease in sperm number under IHH conditions $(\mathrm{P}<0.05)$, as observed in Figure 4. Melatonin in the doses used in this study did not have any effect.

\section{DISCUSSION}

The protective role of melatonin against oxidative stress in rats exposed to intermittent hypobaric hypoxia was analyzed in this study. Oxidative stress can be triggered by a series of endogenous and exogenous factors, exposure to intermittent hypobaric hypoxia being one of them (Farias et al., 2010; Vargas et al., 2011). Exposure to high altitudes is associated with an increase in the production of reactive oxygen species, which are generated during the phase of reoxygenation of intermittent hypobaric hypoxia and contributes to the physiological responses (Nanduri et al., 2008). The main cause of oxidative stress is lower availability of oxygen as it converts to $\mathrm{H}_{2} \mathrm{O}$ by cytochrome oxidase. Hypoxia appears to affect enzyme activities such as superoxide dismutase (SOD), glutathione reductase (GSR) and glutathione peroxidase (GPX), which are usually reduced (Maiti et al., 2006). Recently, studies have demonstrated melatonin interactions with many
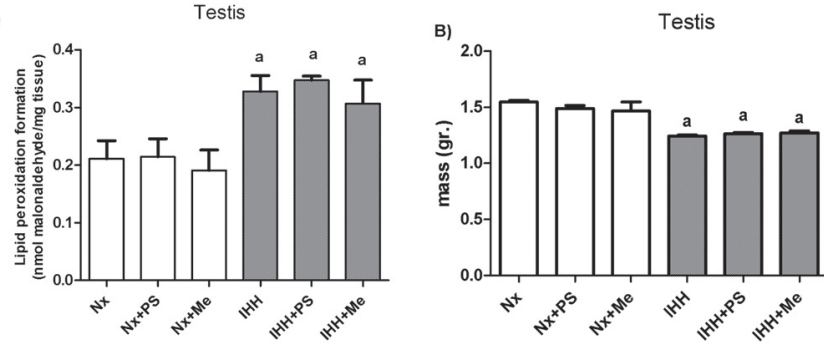

c)

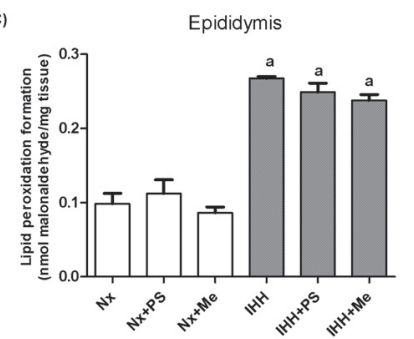

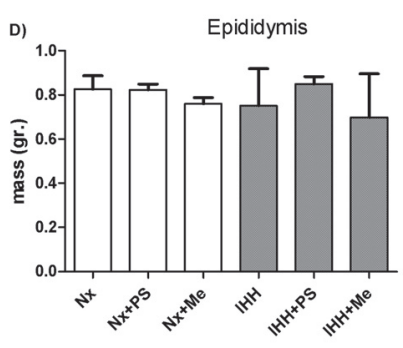

Figure 3. Levels of lipid peroxidation and organ size in testis and epididymis after IHH: Rats were submitted to intermittent hypobaric hypoxia $(\mathrm{IHH})$ or normobaric $(\mathrm{Nx})$ condition, with or without treatment of melatonin (Me). PS: rats treated with physiological $\mathrm{NaCl}$ solution. At the end of treatment (32 days), lipid peroxidation and organ size were determined in testis $(A, B)$ and epididymis $(C, D)$. Bars indicate the mean SD $(n=6)$. a $p<0.05$ ( $\mathrm{Hx}$ versus $\mathrm{Nx}) ; \mathrm{b} \mathrm{p}<0.05$.

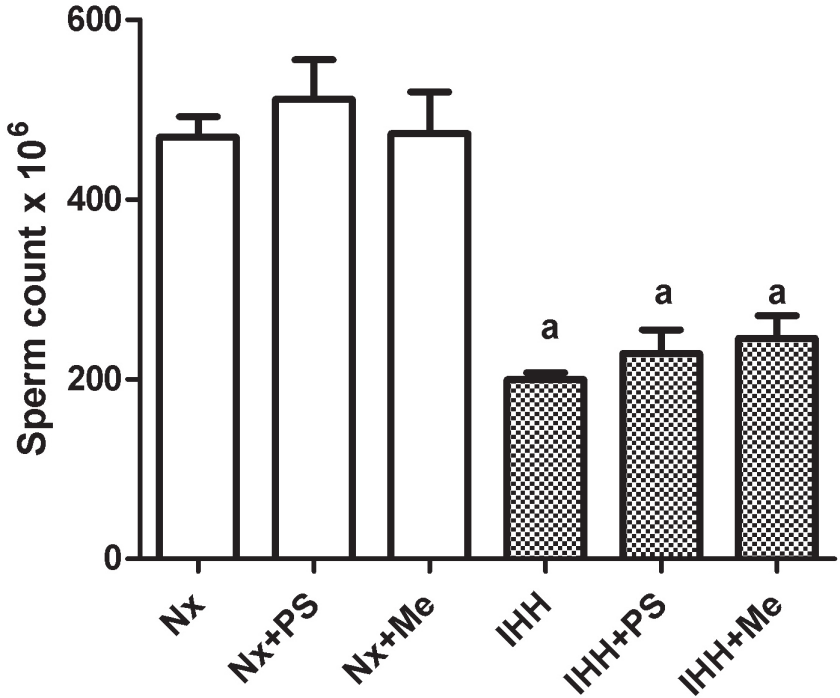

Figure 4. Effect of intermittent hypobaric hypoxia in sperm number: Rats were submitted to intermittent hypobaric hypoxia (IHH) or normobaric (Nx) condition, with or without treatment of melatonin (Me). PS: rats treated with physiological $\mathrm{NaCl}$ solution. At the end of treatment (32 days), epidydimal cauda spermatozoa were counted. $\mathrm{Hx}$ induced a significant decrease in sperm count, which was not prevented by melatonin treatment. Bars indicate the mean SD $(n=6)$. a $p<0.05$. 
physiological processes and diseases (Peliciari-Garcia et al., 2011). Therefore, the effects of melatonin could depend on physiological processes of the organs when these are subjected to environmental stress like IHH.

Little is known about the level of oxidative damage suffered by cell structures in several organs and tissues exposed to high altitude. The study of lipid oxidative damage by estimating malonydialdehyde (MDA) content as a product of lipid peroxidation has been performed on humans, as well as animal models (Moller et al., 2001; Joanny et al., 2001; Radak et al., 1994; Kurmar et al., 1999).

These studies have demonstrated that melatonin plays a protective role in heart, lung and kidney in animals exposed to intermittent hypobaric hypoxia since intermittent lipid peroxidation results in lower malonydialdehyde content in such tissues. The effect of melatonin was corroborated by changes in the organ mass. It is interesting to note that melatonin membrane receptors like MT1 and MT2 have been described in heart, lung, liver and kidney (Sanchez-Hidalgo et al., 2009; Ishii et al., 2009). Authors (Nakanishi et al. (1995) have reported that exposure to hypobaric hypoxia induced at 5,000 meters above see level results in increased oxidative stress in heart, lungs, kidneys and liver. However, these authors did not consider the melatonin effect.

Our results showed that the administration of melatonin to rats induced lipid peroxidation and an increase in liver mass that was not affected by melatonin exposure when injected into the experimental animals. Despite the enormous amount of data supporting the idea of melatonin as a liver protective agent, it should be noted that there are also other reports that have indicated no hepato-protective effect of melatonin to the effect of 2-nitropropane and ethanol in rat liver, which supports our results (Mathes, 2010). On the other hand, lower rates of ROS generation in the liver and decreases in mitochondrial energy metabolism has been reported in rats subjected to hypobaric hypoxia (Costa et al., 1993; NouetteGaulain et al., 2011 and Farías et al., 2005a).

The present study demonstrated that intermittent hypobaric hypoxia induces lipid peroxidation in testis and epididymis, as previously reported (Farias et al., 2010; Vargas et al, 2011). However, in the aforementioned studies melatonin did not have any effect with the doses used in contrary to other reports where melatonin had a protective role in testis and spermatogenesis of rats subjected to intermittent hypobaric hypoxia (Hartley et al., 2009; Bustos-Obregón et al., 2010; Vargas et al., 2011); Ahmad \& Haldar (2010) as well as hamsters and rats, where melatonin seems to act directly on Leydig cells to suppress testosterone release in vitro. When administered orally at $10 \mathrm{mg} / \mathrm{kg}$ bodyweight, melatonin has been described as a counteracting substance for testis and spermatogenesis damage in rats subjected to intermittent hypobaric hypoxia (Vargas et al., 2011). The present results showed that melatonin, with the doses given via intraperitoneal, had no protective effect in testis and epididymis. Furthermore, it has been reported that injecting hamsters with melatonin induced damage in testis by decreasing levels of $\mathrm{LH}$ and FSH (Tamarkin et al., 1976).

Some authors have reported that melatonin treatment induced a marked reduction in sperm quality and did not prevent the reduction in sperm concentration under an ischemia/reperfusion condition (Oosthuizen et al. 1986; Kurcer et al., 2010), which concurs with the results of the present work. Luboshitzky et al. (2002) reported that melatonin administration (3mg) is associated with decreased semen quality in healthy men, probably through the inhibition of aromatase at the testicular level. Aromatase is the terminal enzyme responsible for forming estrogens from androgens and it plays a physiological role in the maintenance of male gonadal functions (Carreau et al., 2001). This enzyme is expressed in Leydig cells, Sertoli cells, germ cells and ejaculated spermatozoa (Carreau and Hess, 2010) in animals and humans. In conclusion, melatonin plays a protective role in heart, lung and kidney under intermittent hypobaric hypoxia conditions.

\section{ACKNOWLEDGMENTS}

We are grateful to Yanet Guíñez for her secretarial support. This work was supported by DIUFRO grant 2011-DI116001 (JF) and Fondecyt \#1080482 (GMC), and Convenio de desempeño (GMC), Universidad de Tarapacá-Mineduc, Chile is greatly appreciated.

\section{REFERENCES}

AHMAD R, HALDAR C. (2010). Effect of intra-testicular melatonin injection on testicular functions, local and general immunity of a tropical rodent Funambulus pennant. Endocr. 37:479-488.

BLOKHINA O, VIROLAINEN E, FAGERSTEDT KV (2003) Antioxidants, oxidative damage and oxygen deprivation stress: a review. Ann Bot. 91; 179-94.

BUSTOS-OBREGÓN E, CASTRO-SÁNCHEZ R, RAMOS GONZÁLEZ B. AND TORRES-DÍAZ L (2010) Rat spermatogenesis damage in intermittent hypobaric hypoxia and the protective role of melatonin. II: testicular parameters. Int. J. Morphology. 28(2): 537-547.

CARREAU S AND HESS RA (2010) Oestrogens and spermatogenesis. Philos Trans R Soc Lond B Biol Sci. 365(1546):1517-35.

CARREAU S, BOURGUIBA S, LAMBARD S, GALERAUD-DENIS I, GENISSEL C, BILINSKA B, BENAHMED M AND LEVALLET J (2001) Aromatase expression in male germ cells. J Steroid Biochem Mol Biol. 79(1-5):203-8.

COSTA EJ, LOPES RH, LAMY-FREUND MT (1995) Permeability of pure lipid bilayers to melatonin. J Pineal Res 1995. 19:123-126.

COSTA LE, LLESUY S, BOVERIS A (1993) Active oxygen species in the liver of rats submitted to chronic hypobaric hypoxia. Am J Physiol. 264 (6 Pt 1): C1395-400.

FARÍAS JG, BUSTOS-OBREGÓN E, ORELLANA R, BUCAREY, JL, QUIROZ E, REYES JG (2005a) Effects of chronic hypobaric hypoxia on testis histology and round spermatid oxidative metabolism. Andrologia. 37:47-52.

FARÍAS JG, PUEBLA M, ACEVEDO A, TAPIA P, GUTIÉRREZ E, ZEPEDA A, JUANTOK C, CALAF G, REYES, J (2010) Oxidative Stress in Testis and Epididymis Under Intermittent Hypobaric Hypoxia in Rats: Protective Role of Antioxidant Supplementation. Journal of Andrology. 31(3):314-321.

GERMACK R, LEÓN-VELARDE F, VALDÉS R, FARÍAS J, SOTO G, RICHALET JP (2002) Effect of intermittent hypoxia on cardiovascular function, adrenoceptors and muscarinic receptors in Wistar rats. Experimental Physiology 84: 4-12.

GITTO E, AVERSA S, REITER RJ, BARBERI1 I, PELLEGRIN S (2011) Update on the use of melatonin in pediatrics. J. Pineal Res. 50:21-28.

HARTLEY R, CASTRO-SÁNCHEZ R, RAMOS-GONZÁLEZ B AND BUSTOS-OBREGÓN E (2009) Rat spermatogenesis damage in intermittent hypobaric hypoxia and the protective role of melatonin. I: Caudal Epididymal spermatozoa. Int. J. Morphology. 27(4): 1275-1284.

ISHII H, TANAKA N, KOBAYASHI M, KATO M, SAKUMA Y (2009) Gene structures, biochemical characterization and distribution of rat melatonin receptors. J Physiol Sci. 59; 37-47.

JALIL J, BRAUN S, CHAMORRO G, CASANEGRA P, SALDÍAS F, BEROÍZA T, FORADORI A, RODRÍGUEZ R, MORALES M (1994) Cardiovascular response to exercise at high altitude in workers chronically exposed to intermittent hypobaric hypoxia. 122(10):1120-1125. 
JOANNY P, STEINBERG J, ROBACH P, RICHALET JP, GORTAN C, GARDETTE B, JAMMES Y (2001) Operation Everest III (Comex'97): the effect of simulated sever hypobaric hypoxia on lipid peroxidation and antioxidant defence systems in human blood at rest and after maximal exercise. Resuscitation. 49(3); 307-14.

KÜCÜKAKIN B, GÖGENUR I, REITER RJ, ROSENBERG J (2009) Oxidative Stress in Relation to Surgery: Is There a Role for the Antioxidant Melatonin?. Journal of Surgical Research. 152: 338-347.

KÜCÜKAKIN B, GÖGENUR I, ROSENBERG J (2007) Melatonin against surgical stress. Ugeskr Laeger. 169(14); 1306-8

KUMAR D, BANSAL A, THOMAS P, SAIRAM M, SHARMA SK, MONGIA SS, SINGH R, SELVAMURTHY W (1999) Biochemical and immunological changes on oral glutamate feeding in male albino rats. Int J Biometeorol. 42(4); 201-4.

KURCER Z, HEKIMOGLU A, ARAL F, BABA F AND SAHNA E (2010) Effect of melatonin on epididymal sperm quality after testicular ischemia/reperfusion in rats. Fertil Steril. 93(5):1545-9.

LUBOSHITZKY R, SHEN-ORR Z, NAVE R, LAVI S AND LAVIE P (2002) Melatonin administration alters semen quality in healthy men. J Androl. 23(4):572-8

MAITI P, SINGH SB, SHARMA AK, MUTHURAJU S, BANERJEE PK, ILAVAZHAGAN G (2006) Hypobaric hypoxia induces oxidative stress in rat brain. Neurochem Int. 49(8); 709-16.

MATHES AM (2010) Hepatoprotective actions of melatonin: Possible mediation by melatonin receptors. World J Gastroenterol.16(48): 60876097.

MOLLER P, LOFT S, LUNDBY C, OLSEN NV (2001) Acute hypoxia and hypoxic exercise induce DNA strand breaks and oxidative DNA damage in humans. FASEB J. 15(7); 1181-6.

NAKANISHI K, TAJIMA F, NAKAMURA A, YAGURA S, OOKAWARA T, YAMASHITA H, SUZUKI K, TANIGUCHI N, OHNO H (1995) Effects of hypobaric hypoxia on antioxidant enzymes in rats. J Physiol. 489(3); 869-76.

NANDURI J, YUAN G, KUMAR GK, SEMENZA GL, PRABHAKAR NR (2008) Transcriptional responses to intermittent hipoxia. Respiratory Physiology \& Neurobiology 164: 277-281.

NOUETTE-GAULAIN K, BIAIS M, SAVINEAU JP, MARTHAN R, MAZAT JP, LETELLIER T, SZTARK F (2011) Chronic hypoxia-induced alterations in mitochondrial energy metabolism are not reversible in rat heart ventricles. Can J Physiol Pharmacol. 89(1); 58-66.

OKUTAN H, SAVAS C, DELIBAS N (2004) The antioxidant effect of melatonin in lung injury after aortic occlusion-reperfusion. Interact CardioVasc Thorac Surg. 3:519-522.
OOSTHUIZEN JMC, BORNMAN MS AND SCHULENBURG GW (1986) Melatonin impairs sperm motility-a novel finding. S. Afr. Med. 70:566.

PELICIARI-GARCÍA RA, ZANQUETTA MM, ANDRADE-SILVA J, GOMES DA, BARRETO-CHAVES ML, CIPOLLA-NETO J (2011) Expression of circadian clock and melatonin receptors within cultured rat cardiomyocytes. Chronobiol Int. 28(1):21-30.

RADAK Z, ASANO K, LEE KC, OHNO H, NAKAMURA A, NAKAMOTO H, GOTO S (1997) High altitude training increases reactive carbonyl derivatives but not lipid peroxidation in skeletal muscle of rats. Free Radic Biol Med. 22(6); 1109-14

RADAK Z, LEE K, CHOI W, SUNOO S, KIZAKI T, OH-ISHI S, SUZUKI K, TANIGUCHI N, OHNO H, ASANO K (1994) Oxidative stress induced by intermittent exposure at a simulated altitude of $4000 \mathrm{~m}$ decreases mitochondrial superoxide dismutase content in soleus muscle of rats. Eur J Appl Physiol Occup Physiol.69(5); 392-5.

REITER RJ, TAN D, MANCHESTER LC, QI W (2001) Biochemical Reactivity of Melatonin with Reactive Oxygen and Nitrogen Species. Cell Biochemistry and Biophysics. 34: 237-256.

RICHALET JP, VARGAS M, JIMÉNEZ D, ANTEZANA AM, HUDSON C, CORTÉS G, OSORIO J, LEÓN G (2002) Chilean miners commuting from sea level to $4500 \mathrm{~m}$ : A prospective study. High. Alt. Med. Biol. 3:159-166.

SÁNCHEZ-HIDALGO M, GUERRERO JM, CARRASCOSA-SALMORAL M-P, NARANJO M-C, LARDONE PJ, ALARCÓN C (2009) Decreased MT1 and MT2 melatonin receptor expression in extrapineal tissues of the rat during physiological aging. J. Pineal Res. 46; 29-35.

SEREL TA, ÖZGUNNER F. AND SOYUPEK S (2004) Prevention of shock wave-induced renal oxidative stress by melatonin: an experimental study. Urol. Res 32:69-71.

TAMARKIN L, WESTROM WK, HAMILL AI, GOLDMAN BD (1976) Effect of melatonin on the reproductive systems of male and female Syrian hamsters: a diurnal rhythm in sensitivity to melatonin. Endocrinology. 99(6):1534-41

TOMÁS-ZAPICO C, COTO-MONTES A (2005) A proposed mechanism to explain the stimulatory effect of melatonin on antioxidative enzymes. J. Pineal Res. 39:99-104.

VARGAS A, BUSTOS-OBREGÓN E, HARTLEY R (2011) Effects of hypoxia on epididymal sperm parameters and protective role of ibuprofen and melatonin. Biol Res. 44: 161-167. 
